\title{
Clinical Reasoning: A 71-Year-Old Man Presenting With Acute Onset Dysarthria and Dysphagia
}

Gregorio Spagni, MD, Luca Tricoli, MD, Anna Modoni, MD, PhD, Mauro Monforte, MD, PhD, Giacomo Della Marca, MD, PhD, and Valerio Brunetti, MD

Neurology ${ }^{\circledR}$ 2021;96:180-184. doi:10.1212/WNL.0000000000010816

\section{Section 1}

A 71-year-old man presented to the emergency department with sudden onset of dysarthria and dysphagia. The patient had arterial hypertension and unspecified tachyarrhythmia. Recently, he was evaluated for difficulties in fine motor skills and rest tremor of the left hand and he was diagnosed with vascular parkinsonism. His medical history was otherwise unremarkable. He denied recent fever or infections. The neurologic examination revealed a severe dysarthria, a positive finger-to-nose test on the left side, a slight hypomimia, and postural and rest tremor of the left arm. The patient was able to walk independently and Romberg sign was negative. Deep tendon reflexes were normally elicitable and symmetric and plantar responses were flexor. Light touch, pinprick, position, and vibration sense were intact. Blood pressure was mildly elevated (160/90 mm Hg), heart rate was rhythmic, and the patient was afebrile. Given the abrupt symptom onset, a cerebrovascular etiology was first suspected. The patient underwent urgent brain CT scan, which was unremarkable, and CT angiography (CTA) (figure). After the CT scan, the symptoms progressively improved and then completely subsided in about 1 hour.

\section{Questions for Consideration:}

1. How would you describe the brain CTA findings (figure)?

2. How would you manage this patient?

\author{
Correspondence \\ Dr. Monforte \\ mauro.monforte@gmail.com
}

\section{GO TO SECTION 2}



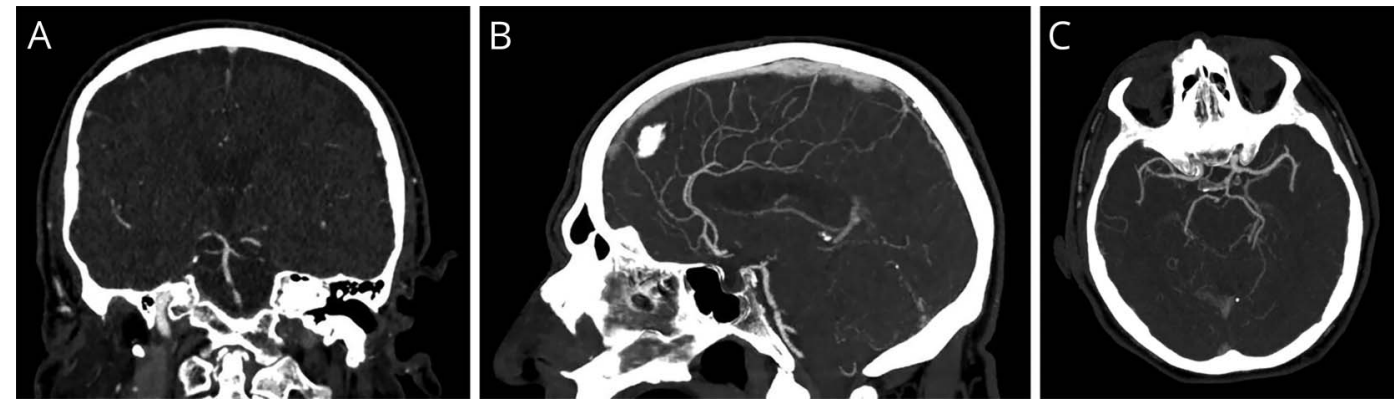

Coronal (A) and sagittal (B) sections show severe stenosis of the basilar artery; axial view (C) shows the middle cerebral arteries and the posterior cerebral arteries.

\section{Section 2}

The brain CTA showed a severe stenosis of the middle segment of the basilar artery (BA) (figure). Given the complete resolution of symptomatology, the patient was considered not eligible for reperfusion therapy. Since the neurologic deficits were consistent with a posterior circulation stroke, the BA stenosis was considered "symptomatic" and medical treatment with dual antiplatelet therapy (clopidogrel + aspirin) plus high-dose statin was started. He was admitted to the stroke unit. The following day, during the late afternoon, the symptoms relapsed. Urgent brain CT scan was again unremarkable. The symptoms progressively improved to resolve completely on the following day morning. On day 3 , another episode of dysarthria lasting around 5 hours occurred. Standard brain MRI scan revealed no acute/subacute ischemic lesions, only showing a mild leukoaraiosis due to chronic ischemic insult. Stenting of BA was not taken into account because current evidence does not support stenting of symptomatic intracranial stenosis. ${ }^{1}$

\section{Questions for Consideration:}

1. What differential diagnosis should be considered?

2. Which diagnostic tests would you perform? 


\section{Section 3}

Even though brain MRI showed no ischemic lesions, a cerebrovascular etiology could not be ruled out. Indeed, it is well known that in ischemic stroke, diffusion-weighted imaging yields a false-negative rate of around $17 \%$, particularly in brainstem and mild strokes (NIH Stroke Scale score $<4$ ). ${ }^{2,3}$ In our patient, it could be hypothesized that hemodynamic hypoperfusion in the brainstem territories downstream the stenosis could have resulted in TIA. The most common mechanism underlying ischemic stroke in the BA territory is by far hemodynamic, associated with large artery occlusive disease, and TIA, isolated or followed by stroke, is a frequent presentation of BA atherosclerosis. ${ }^{4}$ Alternatively, the atheromatous plaque of BA could have led to a temporary occlusion of the penetrating vessels (branch atheromatous disease) and, in turn, to the patient's symptomatology. ${ }^{5}$

In amyloid angiopathy, the irritative effect of the blood products deposition in the cortex and in the subarachnoid space can result in transient, recurrent, and stereotyped focal neurologic deficits (the so-called amyloid spells). ${ }^{6}$ However, this diagnosis was considered unlikely, since susceptibility-weighted imaging did not show findings suggestive of amyloid angiopathy.

Beyond a cerebrovascular etiology, several differential diagnoses have to be considered. In a case of a focal neurologic deficit with spontaneous remission and a relapsing course, one should always consider an epileptic genesis of the disorder. However, seizures usually last for seconds to a few minutes, while the attack duration of our patient lasted several hours. Furthermore, the patient never experienced an alteration of consciousness and could remember the episodes. Both standard EEG and 24-hour EEG registration showed no specific epileptic discharges, making this hypothesis extremely unlikely. A paroxysmal speech disorder might also be due to migraine aura without headache, a rare form of migraine characterized by symptoms suggestive of typical migrainous aura, but not accompanied or followed by headache. ${ }^{7}$ Visual symptoms are the most common, followed by sensory alterations and speech/language disturbances. Symptoms typically last 5-60 minutes. The longer duration of our patient's dysarthric spells ruled out this diagnostic option.

An involvement of the IX, X, and XII cranial nerves can result in dysphagia and dysarthria, and can be due to, among others, neoplastic, traumatic, and inflammatory causes. Neuroimaging ruled out a possible tumoral cause, and the patient had no history of head trauma. It is well known that an immune-mediated cranial neuropathy or brainstem encephalitis might present with dysarthria and dysphagia. ${ }^{8}$ However, autoimmune processes generally have a subacute onset, are characterized by other clinical signs, such as oculomotor deficits, ataxia, and areflexia, and usually do not cause intermittent symptoms.

Considering the patient's age, neurodegenerative diseases are a differential diagnosis. Amyotrophic lateral sclerosis (ALS) with bulbar onset typically presents with dysarthria and dysphagia. However, the symptoms course is usually relentlessly progressive. An acute symptom onset followed by complete resolution and subsequent relapses, as seen in our patient, would be rather atypical for ALS. Conversely, given the fluctuating nature of the symptoms, a neuromuscular transmission (NMT) disorder ought to be considered among the possible differential diagnoses. Myasthenia gravis (MG) is the most common acquired disorder of NMT, and is caused by antibodies targeting proteins expressed at the postsynaptic side of the neuromuscular junction, which results in fluctuating muscle weakness. Antibodies to the nicotinic acetylcholine receptor are detected in around $85 \%$ of cases and to muscle-specific tyrosine kinase in around 5\%. Most patients present ocular symptoms, such as ptosis and diplopia, fatigability of the upper and lower limb muscles, and bulbar symptoms, such as dysarthria and dysphagia. Our patient had no history of ptosis or diplopia or of exaggerated muscle fatigability.

\section{Questions for Consideration:}

1. What is the most likely diagnosis and what diagnostic examinations would you perform?

2. How would you manage this patient?

GO TO SECTION 4 


\section{Section 4}

The patient underwent 3-Hz repetitive nerve stimulation protocol on the nasalis muscle with facial nerve stimulation and on the trapezius muscle with accessory nerve stimulation. A compound muscle action potential decrement of $\geq 10 \%$ was considered abnormal. The test demonstrated a decremental response with a $U$-shaped pattern. This finding is indicative of a postsynaptic disturbance of NMT, with a sensitivity of up to $80 \%$ in generalized $\mathrm{MG}^{9}{ }^{9}$ The patient was clinically reassessed with an MG-focused neurologic examination, which confirmed the presence of signs of exaggerated muscle fatigability. In more detail, the examination documented diplopia occurring after 10 seconds of sustained upward gaze, dysarthria when continuously speaking for more than 30 seconds, and a mild fatigable weakness of the deltoids and neck flexors (quantitative MG scale [QMG] 6). The positive finger-to-nose test on the left side was still present and it was interpreted as tremor due to parkinsonism. Patient serum was tested for anti-AChR and anti-MuSK antibodies, and the former resulted positive (titer $16.1 \mathrm{nmol} / \mathrm{L}$ ). This confirmed the diagnosis of MG. Thorax CT scan was negative for thymoma. Treatment with pyridostigmine at a dose of $30 \mathrm{mg}$ TID and prednisone $5 \mathrm{mg}$ daily was started, with a clear benefit. Given that the BA stenosis was no longer considered responsible for the patient's symptoms, clopidogrel was stopped; in consideration of the severe grade of the stenosis and the MRI finding of leukoaraiosis, the patient was left on atorvastatin and low-dose aspirin. At the last followup visit, the patient reported no more episodes of dysarthria or other symptoms suggestive of MG and the neurologic examination documented a marked clinical improvement (QMG 1).

\section{Discussion}

Stroke is the leading cause of neurologic disability worldwide and one of the most common neurologic diseases, with an approximate incidence of $670-970$ cases per 100,000 personyears among those aged $65-74$ years. ${ }^{10} \mathrm{MG}$ is a rare disorder with an annual incidence of 8-10 cases per million and an estimated prevalence of 150-250 per million. ${ }^{9}$ Cerebrovascular diseases are considered first in case of an abrupt onset of a focal neurologic deficit, especially in the elderly population. In the described case, the clinical picture was further complicated by the a posteriori incidental finding of a BA stenosis, a plausible cause of a posterior circulation ischemic stroke consistent with the patient's symptoms. On the other hand, a first presentation of MG with an abrupt onset of isolated dysarthria and dysphagia is an extremely rare event. In these cases, the differential diagnosis with cerebrovascular diseases is difficult, as previously reported. ${ }^{11,12}$ Nevertheless, after the acute phase, other symptoms such as fluctuating ptosis and diplopia or progressive respiratory difficulties usually help guide the diagnosis toward an NMT disorder. In our case, negative MRI findings led us to consider other diagnoses beyond cerebrovascular diseases and symptoms fluctuation arose the suspicion of MG. However, when clinical presentation is not clear, a comprehensive neurologic examination is essential to lead the diagnostic process. In the past decades, several reports documented a sharp increase in the incidence of late-onset MG (LOMG, i.e., MG with onset after age 50), especially among men. ${ }^{9}$ LOMG is now the largest MG subgroup. ${ }^{13}$ Nonetheless, the disease is probably still underrecognized and the diagnosis is particularly challenging in the elderly. Prompt identification of MG is of paramount importance because specific treatment may prevent further symptom deterioration and unnecessary drugs can be stopped, assuring the patient a better quality of life.

\section{Study Funding}

No targeted funding reported.

\section{Disclosure}

The authors report no disclosures relevant to the manuscript. Go to Neurology.org/N for full disclosures.

\section{Appendix Authors}

\begin{tabular}{|c|c|c|}
\hline Name & Location & Contribution \\
\hline $\begin{array}{l}\text { Gregorio } \\
\text { Spagni, MD }\end{array}$ & $\begin{array}{l}\text { Institute of Neurology, } \\
\text { Università Cattolica del } \\
\text { Sacro Cuore, Rome, Italy }\end{array}$ & $\begin{array}{l}\text { Drafting of the manuscript; } \\
\text { study concept and design; } \\
\text { acquisition, analysis, and } \\
\text { interpretation of data; } \\
\text { critical revision of the } \\
\text { manuscript for important } \\
\text { intellectual content }\end{array}$ \\
\hline $\begin{array}{l}\text { Luca } \\
\text { Tricoli, MD }\end{array}$ & $\begin{array}{l}\text { Institute of Neurology, } \\
\text { Università Cattolica del } \\
\text { Sacro Cuore, Rome, Italy }\end{array}$ & $\begin{array}{l}\text { Acquisition, analysis, and } \\
\text { interpretation of data; } \\
\text { critical revision of the } \\
\text { manuscript for important } \\
\text { intellectual content }\end{array}$ \\
\hline
\end{tabular}

\begin{tabular}{|c|c|c|}
\hline $\begin{array}{l}\text { Anna } \\
\text { Modoni, } \\
\text { MD, PhD }\end{array}$ & $\begin{array}{l}\text { U.O.C. } \\
\text { Neurologia-Fondazione } \\
\text { Policlinico Universitario “A. } \\
\text { Gemelli" IRCCS, Rome, Italy }\end{array}$ & $\begin{array}{l}\text { Acquisition, analysis, and } \\
\text { interpretation of data; } \\
\text { critical revision of the } \\
\text { manuscript for important } \\
\text { intellectual content }\end{array}$ \\
\hline
\end{tabular}

\begin{tabular}{|c|c|c|}
\hline $\begin{array}{l}\text { Mauro } \\
\text { Monforte, } \\
\text { MD, PhD }\end{array}$ & $\begin{array}{l}\text { U.O.C. } \\
\text { Neurologia-Fondazione } \\
\text { Policlinico Universitario "A. } \\
\text { Gemelli" IRCCS, Rome, Italy }\end{array}$ & $\begin{array}{l}\text { Study concept and design; } \\
\text { acquisition, analysis, and } \\
\text { interpretation of data; } \\
\text { critical revision of the } \\
\text { manuscript for important } \\
\text { intellectual content }\end{array}$ \\
\hline $\begin{array}{l}\text { Giacomo } \\
\text { Della } \\
\text { Marca, MD, } \\
\text { PhD }\end{array}$ & $\begin{array}{l}\text { Institute of Neurology, } \\
\text { Università Cattolica del } \\
\text { Sacro Cuore; U.O.C. } \\
\text { Neurologia-Fondazione } \\
\text { Policlinico Universitario "A. } \\
\text { Gemelli" IRCCS, Rome, Italy }\end{array}$ & $\begin{array}{l}\text { Acquisition, analysis, and } \\
\text { interpretation of data; } \\
\text { critical revision of the } \\
\text { manuscript for important } \\
\text { intellectual content }\end{array}$ \\
\hline $\begin{array}{l}\text { Valerio } \\
\text { Brunetti, } \\
\text { MD }\end{array}$ & $\begin{array}{l}\text { U.O.C. } \\
\text { Neurologia-Fondazione } \\
\text { Policlinico Universitario “A. } \\
\text { Gemelli" IRCCS, Rome, Italy }\end{array}$ & $\begin{array}{l}\text { Study concept and design; } \\
\text { acquisition, analysis, and } \\
\text { interpretation of data; } \\
\text { critical revision of the } \\
\text { manuscript for important } \\
\text { intellectual content; study } \\
\text { supervision }\end{array}$ \\
\hline
\end{tabular}

\section{References}

1. Powers WJ, Rabinstein AA, Ackerson T, et al. Guidelines for the early management of patients with acute ischemic stroke: 2019 update to the 2018 guidelines for the early management of acute ischemic stroke: a guideline for healthcare professionals from the American Heart Association/American Stroke Association. Stroke 2019;50:e344-e418. 
2. Chalela JA, Kidwell CS, Nentwich LM, et al. Magnetic resonance imaging and computed tomography in emergency assessment of patients with suspected acute stroke: a prospective comparison. Lancet 2007;369:293-298.

3. Majidi S, Luby M, Lynch JK, et al. MRI-based thrombolytic therapy in patients with acute ischemic stroke presenting with a low NIHSS. Neurology 2019;93:e1507-e1513.

4. Voetsch B, DeWitt LD, Pessin MS, Caplan LR. Basilar artery occlusive disease in the New England Medical Center Posterior Circulation Registry. Arch Neurol 2004;61: 496-504.

5. Petrone L, Nannoni S, Del Bene A, Palumbo V, Inzitari D. Branch atheromatous disease: a clinically meaningful, yet unproven concept. Cerebrovasc Dis 2016;41:87-95.

6. Charidimou A, Law R, Werring DJ. Amyloid "spells" trouble. Lancet 2012;380:1620.

7. Aiba S, Tatsumoto M, Saisu A, et al. Prevalence of typical migraine aura without headache in Japanese ophthalmology clinics. Cephalalgia 2010;30:962-967.
8. Winer JB. Bickerstaff's encephalitis and the Miller Fisher syndrome. J Neurol Neurosurg Psychiatry 2001;71:433-435.

9. Gilhus NE, Tzartos S, Evoli A, Palace J, Burns TM, Verschuuren J. Myasthenia gravis Nat Rev Dis Primers 2019;5:30.

10. Roger VL, Go AS, Lloyd-Jones DM, et al. Heart disease and stroke statistics: 2011 update: a report from the American Heart Association. Circulation 2011;123:e18-e209.

11. Tremolizzo L, Giopato F, Piatti ML, Rigamonti A, Ferrarese C, Appollonio I. Myasthenia gravis mimicking stroke: a case series with sudden onset dysarthria. Neurol Sci 2015;36:895-898.

12. Montero-Odasso M. Dysphonia as first symptom of late-onset myasthenia gravis. J Gen Intern Med 2006;21:C4-C6.

13. Cortes-Vicente E, Alvarez-Velasco R, Segovia S, et al. Clinical and therapeutic features of myasthenia gravis in adults based on age at onset. Neurology 2020;94:e1171-e1180.

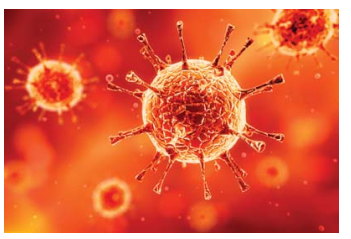

\section{COVID-19 and Neurologic Disease: Call for Papers!}

The editors of Neurology are interested in papers that address the neurological aspects of COVID-19 infection and challenges to the management of patients with chronic neurological conditions who have, or are at risk for, the infection. Relevant papers that pass initial internal review will undergo expedited peer review and online publication. We will consider papers posted in preprint servers.

Submit observational studies and clinical trials as Articles and case series and case reports under the Clinical/Scientific Notes category to https://submit.neurology.org/ today!

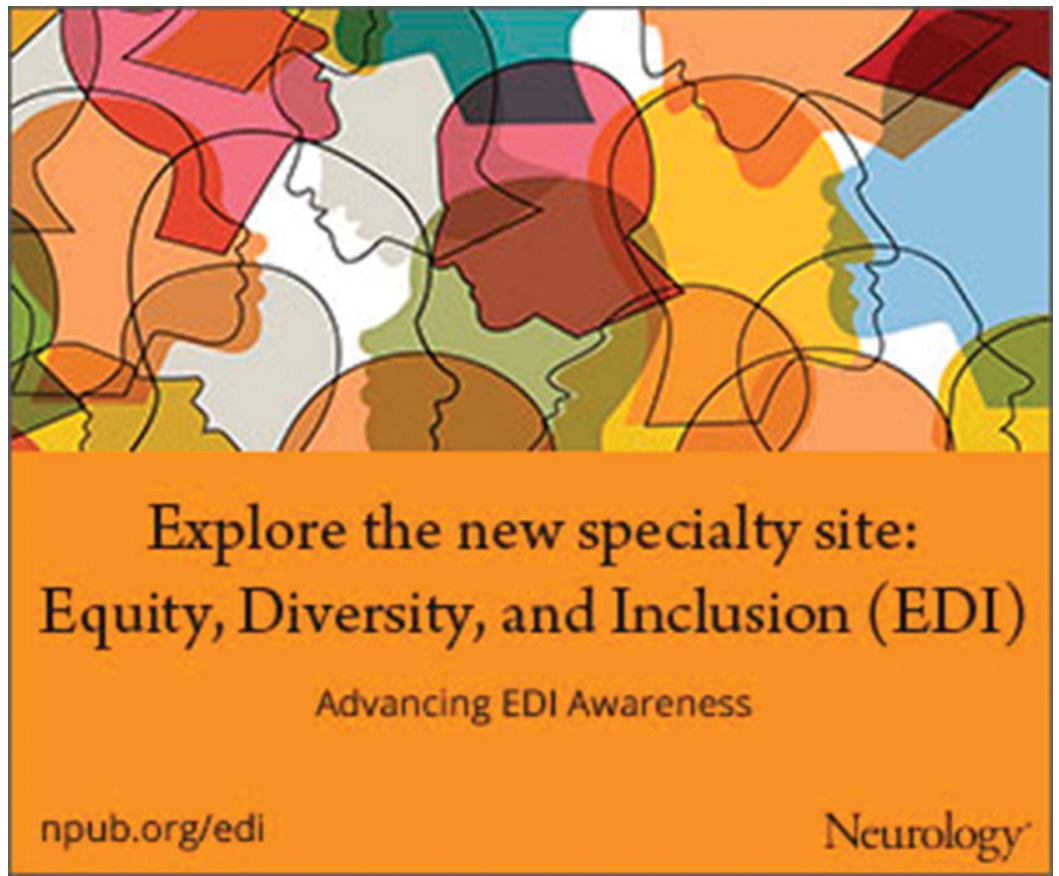




\section{Neurology}

\section{Clinical Reasoning: A 71-Year-Old Man Presenting With Acute Onset Dysarthria and Dysphagia}

Gregorio Spagni, Luca Tricoli, Anna Modoni, et al.

Neurology 2021;96;180-184 Published Online before print September 11, 2020

DOI 10.1212/WNL.0000000000010816

This information is current as of September 11, 2020

\section{Updated Information \&} Services

References

Subspecialty Collections

Permissions \& Licensing

Reprints including high resolution figures, can be found at: http://n.neurology.org/content/96/4/180.full

This article cites 13 articles, 4 of which you can access for free at: http://n.neurology.org/content/96/4/180.full\#ref-list-1

This article, along with others on similar topics, appears in the following collection(s):

All Cerebrovascular disease/Stroke

http://n.neurology.org/cgi/collection/all_cerebrovascular_disease_strok e

All Neuromuscular Disease

http://n.neurology.org/cgi/collection/all_neuromuscular_disease Autoimmune diseases

http://n.neurology.org/cgi/collection/autoimmune_diseases

Information about reproducing this article in parts (figures,tables) or in its entirety can be found online at:

http://www.neurology.org/about/about_the_journal\#permissions

Information about ordering reprints can be found online:

http://n.neurology.org/subscribers/advertise

Neurology ${ }^{\circledR}$ is the official journal of the American Academy of Neurology. Published continuously since 1951, it is now a weekly with 48 issues per year. Copyright @ 2020 American Academy of Neurology. All rights reserved. Print ISSN: 0028-3878. Online ISSN: 1526-632X.

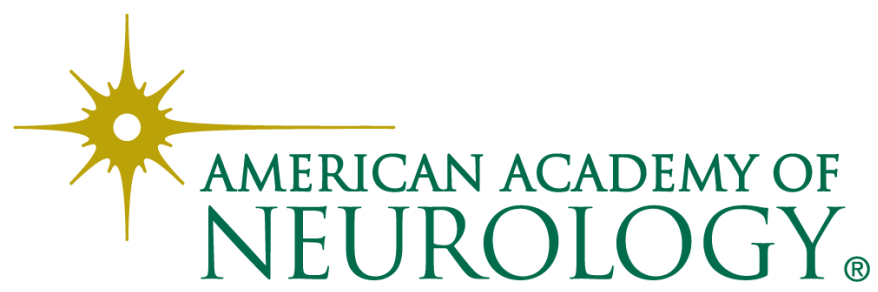

